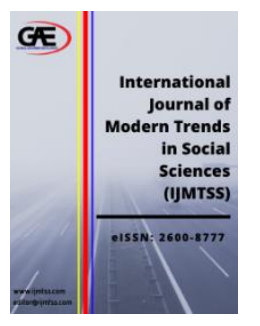

\author{
International Journal of Modern Trends in \\ Social Sciences (IJMTSS) \\ Journal Website: http://ijmtss.com/ \\ eISSN: $2600-8777$
}

\title{
MALAYSIAN AUDIENCES REACTION OF NEWS FRAME SETTING TOWARDS LGBT ISSUES
}

\author{
Julia Wirza Mohd Zawawi*1, Hamisah Hassan ${ }^{2}$, Kho Suet $\mathrm{Nie}^{3}$, Norliana Hashim ${ }^{4}$ \\ 1 Department of Communication, Universiti Putra Malaysia, Malaysia \\ Email: wirza@upm.edu.my \\ 2 Department of Communication, Universiti Putra Malaysia, Malaysia \\ Email: hamisah@upm.edu.my \\ 3 School of Media and Communication, Taylor's University, Malaysia \\ Email: SuetNie.Kho@ taylors.edu.my \\ 4 Department of Communication, Universiti Putra Malaysia, Malaysia \\ Email: h_norliana@upm.edu.my \\ * Corresponding Author
}

\section{Article Info:}

Article history:

Received date:29.11.2019

Revised date: 12.12 .2019

Accepted date: 13.03.2020

Published date: 15.03.2020

\section{To cite this document:}

Zawawi, J. W. M., Hassan, H., Kho, S. N., \& Hashim, N. (2020). Malaysian Audience Reaction of News Frame Setting Towards LGBT Issues. International Journal of Modern Trends in Social Sciences, 3 (11), 118124.

DOI: $10.35631 / \mathrm{IJMTSS} .3110010$.

\begin{abstract}
:
The trending and increasing openness of news reporting has caused the media industry to shift and increasingly report news that was once considered taboo to the mass audiences. The high acceptance and rate of feedback from the readers boost the rate of coverage on taboo issues. Lesbian, Gay, Bisexual, and Transgender or commonly known as LGBT is an issue that is gaining traction on online news portals. Therefore, the main aim of this conceptual article is to discuss the effects of news presentation regarding this issue using the framing theory from three main aspects which are (i) cognitive (ii) response (attitude) and (iii) behavior (acceptance or rejection). This study can be used to shape a theoretical expectation of LGBT issues that are being presented by an online news portal today.
\end{abstract}

Keywords:

Framing, Frame Setting, Cognitive, LGBT, Attitude

\section{Introduction}

Society has started to believe that the changes brought about by the new media technology are inevitable and must be adopted by all. The transition from traditional media to new media Copyright $\odot$ GLOBAL ACADEMIC EXCELLENCE (M) SDN BHD - All rights reserved 
forces users to adopt many changes whether it is from perspective of socialization, entertainment, education, political involvement, reportage, and so on. The use of social media such as Facebook, Instagram, and Twitter have become the lifeblood of many users today. Up until 2018, 68 percent people uses Facebook and 74 percent surfs the web at least once a day in America (Rebecca \& Yu Won Oh, 2018).

One of the basic technologies that is popularly used is the Internet. Internet is used in various medium that receive and transmit information and data. The process communication using the Internet is one of the most important mechanisms especially in the era of digital revolutionary applications such as computers and smartphones (Peckham, 2013). Drastic technological development has brought various negative and positive perceptions. As with all technological advancement, technology can bring negative impact once misused.

Political experts concluded that technological and new media development are in fact a fresh breath to the world of democracy. In the past, society face constraints expressing their views and opinions but now with new media, any opinion especially pertaining to government policies and politics can be articulately voiced (Kim et al., 2013; Shah et al., 2001).

As technology advances, it has paved an easier and faster path for all industries, including journalism. Journalists who used to only rely on traditional media to deliver their information and news have transited to online media. These subsequently lead to efforts to attract and encourages consumers to move on to the online media. This situation was discussed by Rebecca $\& \mathrm{Yu}$ Won Oh (2018) on the changes of readers in democratic landscape from informed citizenship to expressive citizenship as the new media give chances to readers to express their opinions.

In Malaysia, news portals and news broadcasting using social media has taken root among readers. Harian Metro, Berita Harian and Utusan Malaysia respectively have focused on news portal and social media in hope to gain more readers. This phenomenon has caused information overload as seen on social media. The piling and flooding of news display on social media has opened a new discussion on how it can provide accurate information to readers.

For example, one of the most popular issues that is discussed in Malaysia is Lesbian, Gay, Bisexual and Transgender issues or more commonly known as LGBT. Through news portals and social media, society can get the latest information. Frequently, the main news that are broadcasted are related to social, politics and economy issues. LGBT is a popular topic for discussion among social media users. The discussion on LGBT is strong as it is considered a taboo topic and considered a human right transgression in a religious-centric Malaysia (Zurairi,2013; Bhavan, 2018). LGBT values also contradict the core of Malaysia as an Islamic state that forbid homosexual relationships as it is seen as immoral, illegal and totally against Islamic principles and laws (Muhammad, 2000).

Hence, this article will discuss LGBT conceptually by using the framing theory on how individuals think and their perceptions on the LGBT issue. This articles also focuses on three main aspects namely the effects on individual cognitive, individual response, and effects on individual attitude when LGBT issues are highlighted by the media.

\section{LGBT in Malaysia}

Discussions about LGBT are closely related to gender. Concept of gender centers around inclination of individuals thought and personality as well as the role of an individual in terms 
of masculinity or femininity. Gender disruption refers to an individual having internal conflicts leading to confusion in acknowledging their identity. Gender disruption can be categorized into two aspects, the first aspect whereby an individual mimic the behaviour or nature of opposite gender and the second aspect whereby an individual is involved in any sexual relationship with the same gender. These are in essence known as LGBT. LGBT also refers to lesbian, gay, bisexual and transgender. (Mohd Izzat, M.A, Muhammad Syahlan, S., Hisham, H., \& Fareed, $\mathrm{H}, 2018)$

Malaysia is known as a country of multi religions, races and ethnicities. And Islam is the official religion of Malaysia. Islam is a religion that certainly forbids same gender relationship. Therefore, since Islamic law is fully implemented in Malaysia, those in the LGBT community are not only doing something against Islam but also against Malaysian law. (Musa Yusuf, O., \& Ahmad Zaharuddin, S.A.S, 2014)

However, in recent years, the issue of LGBT is gaining more prominence among media consumers. The prominence of LGBT issue was partly raised by the minority that has begun to advocate for the human rights of LGBT group. (Mohd Izzat, M.A et al, 2016). Many issues related to LGBT are now discussed openly on social media and undeniably the public are attracted to the discourse of these issues. The public started given their speculation and opinion to discuss about LGBT. The ongoing discussion of the issues of LGBT directly and indirectly affect the reader or audiences.

\section{Individual Cognitive}

The increasing exposure to taboo issues such as LGBT on social media has given an illustration on how effective it is to the audiences. Which news frames is the most dominant and pose the strongest impact to an individual? How effective is a particular news framing towards society? Gamson dan Modigliani (1989) have stated in a discussion of framing theory that framing is an idea of management or storyline that gives meaning to every event that happened. With that, the news frames suggest what kind of issues that are being discussed and how individuals need to understand it. The news frames are manifested through selection, highlighting and description of each issue presented.

Humans think and make decisions for every news that we are exposed to. Information processing that happen in the minds of human beings decide the effectiveness of every news issue that is broadcasted. Framing through selection and highlighting can either help or not help individuals to evaluate news broadcasting that are received.

\section{Knowledge of Frame Setting}

There are too many researches and discussions that have been done about framing and frame building. However, the area of frame setting is an area where researches are still scarce. It is clearly defined that framing is a process where media selects and gives pressure towards certain aspects to make them more prominent and dominant (Entman, 1993). It is considered an individual process that orients their thought on an issue based on received message (Chong \& Druckman, 2007). The definition given by the scholars exhibit the significant role that media frame plays in highlighting an issue. Individuals who consume these media will then process said information cognitively and decide to accept or believe the frames portrayed.

Going back to frame setting, the research of framing highlights that it is a process of evaluating school of thought, issue interpretation, concerns of behavior, perception towards issues and many more. Lately, the focus has started to shift to the question of whether news framing has 
effects on certain issues. There are various possibilities of the effects of framing which are (i) the condition of framing that is used either it is strong, weak or no effect, (ii) describes the basics and mechanisms that explain how effects can give impact, (iii) roles of repetitive and competitive frames to the framing process (Schuk \& Feinholdt, 2014).

Frame setting is not something that can be evaluated and discussed in the context of groups or mass. Media effects are very different to every individual. Everyone's capacity and cognitive tendencies are different from one another. Numerous studies have identified various factors or moderators in individual process of gaining knowledge of issues and personal values such as personal character and individual tendencies. Other factors such as characteristics and interpersonal communication must also be considered. (Schuk \& Feinholdt, 2014).

This conceptual paper is proposing to inspect frame setting using the issue of LGBT. As facts and history go, the discussion and practices of LGBT in Malaysia are not allowed and against the law. Usage of social media such as Facebook however encourages more heated discussions relating to this issue whether directly or indirectly. Academicians has discussed at length the moderators and mediators that would contribute to greater effects of news frames on individuals. The effect here is defined as the level of acceptance on issues that impact individuals behavior and attitude. Individual cognitive capacity is at minimum when it comes to taboo issues such as LGBT. Hence, news broadcasting and issues discussed by the media will determine the level of one's individual cognitive. For example, the more frequent the presentation of LGBT issues, the more it affects the individual's cognition. This cognitive consideration towards LGBT issues play important role into acceptance or rejection of LGBT as well as the frames.

There are researches that explain about belief content. It is a factor towards the effectiveness of news framing. Belief content is the contents of the existing knowledge contained in an individual's mind. If an individual has high preconceived knowledge about LGBT, then the chances of effectiveness of news framing is also high. If an individual is not exposed to the issue of LGBT before, the news presentation or broadcast of LGBT will not leave any effect on them. Factors that impact individual frames of the LGBT issues is an important area to be studied in the context of Malaysia as Malaysia strongly prohibits the practice of same sex relationships.

Thus, conceptually, discussions on the cognitive and thinking elements of LGBT frame setting should be prioritized. These discussions will shed better understanding on individuals level of acceptance and ideas towards LGBT issues. Detailed discussion rooted in the theory of framing is necessary in discussing social issues like this to identify why the issue of LGBT is still being discussed even though it is forbidden in Malaysia. To date, the extent of acceptance and openness of Malaysian society on issues like this is still unknown.

\section{Expression Among Audiences}

With social media, Malaysians have a chance to be more vocal in discussing decisions made by the government. Individuals have more chance to express their views and opinions more openly. Ping Yu \& Yu Won Oh (2018) explained that in shaping society's expression model, emphasis is given to their self-expression in social and entertainment environments. Thus, some approach and measures were introduced by said scholars to anticipate individual expressions from social media like Facebook. 
Among them are (i) sharing information and the private lives of others (ii) sharing someone's content and entertainment interests on social media (iii) interactive political expression, to determine whether they are positively or negatively inclined. It is predicted that the expressions obtained through traditional media and social media are parallel with each other, especially in political aspect. The transformation from informed citizenship to expressive citizenship is also expected. Traditional media which used to only require one-way communication is also changing due to exposure to new media. This is because they can express their opinions through social media.

Boyle, Schmierbach, Armstrong, Cho, McClaskey, McLeod \& Shah (2006) listed a few stages of individual expression. The stages are (i) discussing issues said by family members (ii) voicing out opinions on issues said by other people (iii) sending comments to editors/newspapers on said issue (iv) calling government officers to give comments about a certain issue (v) obtaining feedback from government officers about a certain issue (vi) attending public forums/discussions about an issue (vii) attending rallies as a sign of protest.

Through a research conducted by de Vresse (2005) himself on framing integration process model, one of the elements of the framing process was explained to be frame setting or framing effect. He explained that the effect of the framing itself is split into three main effects. The first one is the information processing effect that involves processes in the individual's schemata and cognitive. The second is the attitude change effect which involves the way of expression of an individual when they are exposed to issues in news through the media. The third is behavior change effect which is the psychological and physical acceptance of an individual towards a news issue broadcasted by the media.

What really should be discussed and examined through this framing theory relating to issues like LGBT is something that is hardly explored in Malaysia. Elements of the expressions discussed by academicians as mentioned above should be used to explore the LGBT issue. The high dominance of Muslim's population and strict legal views structure has become a drive to see media portrayal especially on social media with regards to LGBT issue. Studies should focus on how far news articles on the issue of LGBT influence individuals thinking and thus inflict changes on their acceptance. The focus on sensitive social issues should yield a different result from previous studies that are mostly focused on acceptance of political issues.

\section{Discussion and Conclusion}

The researchers are trying to expand studies from communication scholars and framing especially from the aspect of frame setting. Prior studies in frame setting is more focused on political studies because it was an effort to scan media portrayal towards individuals that would lead to changes in voting power. Articles discussed by the researchers conceptually discussed elements in the frame setting and framing especially in psychological aspects.

Various stages and process in frame setting starts from the cognitive information processing process and proceeds to the attitude change process and the behavior change process. LGBT issue is the main choice and is often discussed in social media and shared with many consumers. The sharing done by them triggers questions that should be pondered. Does the sharing of LGBT issue indicate that the acceptance of mere discussion? Or does that indicate their acceptance of the LGBT society? This is difficult to unravel with only observation and must be explored further. 
Lastly, this article gives a description to the general society on the real effects of mass media. Negative portrayal might bring negative effects while positive portrayal might bring positive effects. Social media sharing does not necessarily mean that it has no meaning, in fact it is capable of making a huge impact. The communication and information technological advances are not something that must only be viewed from a positive angle, but it also has to be observed closely so it does not leave negative effects on the society.

\section{References}

Bhavan, J. (2018). In Mahathir's Malaysia, No Gay Rights and No Free Speech. Retrieved from https://www.scmp.com/week-asia/politics/article/2155228/mahathirs-malaysiano-gay-rights-and-no-free-speech.

Boyle, M.P., Schmierbach, M, Amstrong, C.L., Cho,J., McCluskey,. M, McLeod. D \& Shah, D.V. (2006). Expressive responses to news stories about extremist group: a framing experiment. Journal of Communication, 56, 271-288.

Chong, D. \& Druckman, J.M. (2007). Framing public opinion in competitive democracies. American Political Science Review 101(4), 637-655.

De Vreese, C., H. (2005). News Framing: Theory and Typology. Journal of Information Design, 13 (1), 51-62.

De Vreese, C., H. (2014). Mediatization Of News: The Role of Journalistic Framing. In F. Esser, \& J. Strömback, (Eds.), Mediatization Of Politics: Understanding the Transformation of Western Democracies (pp. 137 - 155). Basingstoke: Palgrave Macmillan.

Entman, R. (1993). Framing - Toward Clarification of a Fractured Paradigm. Journal of Communication, 43 (4). 51-58.

Gamson, W.A \& Modigliani. (1989). Media discourse and public opinion on nuclear power: A constructionist approach. American Journal of Sociology 95(1), 1-37.

Kim, Y., Chen, H.T., Gil de Zuniga, H. (2013). Stumbling upon news on the internet: Effects of incidental news exposure and relative entertainment use on political engagement.

Computer Human Behaviour 29(6), 2607-2614.

Muhammad, S. (2000). Outlines of Criminal Law and Justice in Islam. Selangor, Malaysia: International Law Book Service.

Musa Yusuf, O., \& Ahmad Zaharuddin Sani, A.S. (2014). LGBT, Nature or Ideology? Sharing the experience of a former Practitioner in Malaysia. Journal of Humanities and Social Science 19(12): 62-69.

Mohd Izzat Amsyar, M.A., Muhammad Syahlan, S., Hisham, H., \& Fareed, M.H. (2018). Salah laku LGBT dalam perundangan Malaysia: Undang-undang sebagai mekanisme pembanterasan dan kawalan. Journal of Advanced Research in Social and Behavioural Sciences 13(1): 19-34.

Peckham, M. (2013). Could Nanowire Transistors Rescue Moore's Law From Obsolescence? Retrieve from: http://techland.time.com/2013/05/01/could-nanowire-transistorsrescue-moores-law-from-obsolescence/

Rebecca, P.Y \& Yu, W.O. (2018). Social media and expressive citizenship: Understanding the relationship between social and entertainment expression on Facebook and political participation. Telematics and Informatics 35, 2299-2311.

Schuck, A.R \& Feinholdt. (2014). News framing effect and emotions: Research trends and development. Retrived from: https://www.researchgate.net/publication/299864958_News_Framing_Effects_and_E motions.

Semetko, H., \& Valkenburg, P. (2000). Framing European Politics: A Content Analysis of Press and Television News. Journal of Communication, 50 (2), 93-109. 
Shah, D.V., Kwak, N., \& Holbert, R.L. (2001). "Connecting" and "disconnecting" with civic life: Pattern of internet use and the production of social capital. Political Communication. 18(2), 141-162.

Zurairi, A. R. (2013). Beware of LGBT and Freedom of Religion Movements. Retrieved from http://www.themalaysianinsider.com/malaysia/article/shun-fatwas-from-politiciansmuhyiddin-tells-muslims. 